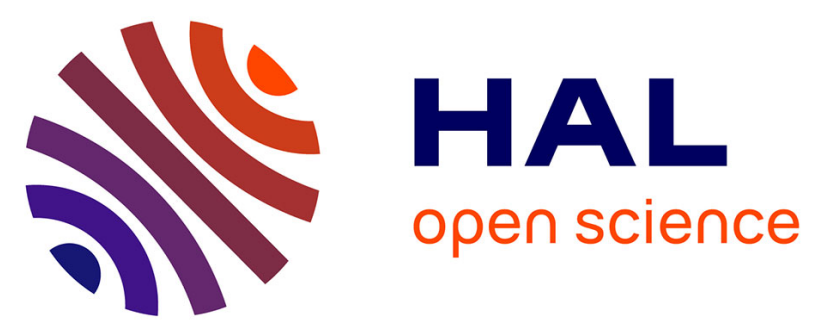

\title{
Deprotonative Metalation of Methoxy-Substituted Arenes Using Lithium 2,2,6,6-Tetramethylpiperidide Experimental and Computational Study
}

Gaku Akimoto, Mai Otsuka, Ryo Takita, Masanobu Uchiyama, Madani Hedidi, Ghenia Bentabed-Ababsa, Frédéric Lassagne, William Erb, Florence Mongin

\section{To cite this version:}

Gaku Akimoto, Mai Otsuka, Ryo Takita, Masanobu Uchiyama, Madani Hedidi, et al.. Deprotonative Metalation of Methoxy-Substituted Arenes Using Lithium 2,2,6,6-Tetramethylpiperidide Experimental and Computational Study. Journal of Organic Chemistry, 2018, 83 (21), pp.13498-13506. 10.1021/acs.joc.8b02397 . hal-01935364

HAL Id: hal-01935364

https://hal-univ-rennes1.archives-ouvertes.fr/hal-01935364

Submitted on 3 Dec 2018

HAL is a multi-disciplinary open access archive for the deposit and dissemination of scientific research documents, whether they are published or not. The documents may come from teaching and research institutions in France or abroad, or from public or private research centers.
L'archive ouverte pluridisciplinaire HAL, est destinée au dépôt et à la diffusion de documents scientifiques de niveau recherche, publiés ou non, émanant des établissements d'enseignement et de recherche français ou étrangers, des laboratoires publics ou privés. 


\title{
Deprotonative Metalation of Methoxy-Substituted Arenes using Lithium 2,2,6,6-Tetramethylpiperidide: Experimental and Computa- tional Study
}

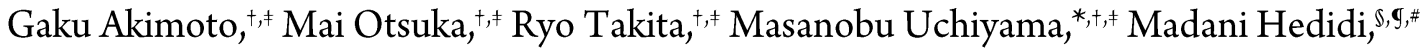 \\ Ghenia Bentabed-Ababsa, ${ }^{\complement}$ Frédéric Lassagne, ${ }^{\circledR}$ William Erb, ${ }^{\S}$ and Florence Mongin ${ }^{*, \S}$ \\ ${ }^{+}$Graduate School of Pharmaceutical Sciences, The University of Tokyo, 7-3-1 Hongo, Bunkyo-ku, Tokyo 113-0033, Japan \\ ${ }^{\ddagger}$ Advanced Elements Chemistry Research Team, RIKEN Center for Sustainable Resource Science, and Elements Chemistry Laborato- \\ ry, RIKEN, 2-1 Hirosawa, Wako-shi, Saitama 351-0198, Japan \\ ${ }^{\circledR}$ Univ Rennes, CNRS, ISCR (Institut des Sciences Chimiques de Rennes) - UMR 6226, F-35000 Rennes, France \\ TLaboratoire de Synthèse Organique Appliquée, Faculté des Sciences Exactes et Appliquées, Université Oran 1 \\ Ahmed Ben Bella, BP 1524 El M’Naouer, 31000 Oran, Algeria
}

\begin{abstract}
The reaction pathways of lithium 2,2,6,6-tetramethylpiperidide (LiTMP)-mediated deprotonative metalation of methoxysubstituted arenes were investigated. Importantly, it was experimentally observed that, whereas TMEDA has no effect on the course of the reactions, the presence of more than stoichiometric amount of $\mathrm{LiCl}$ is deleterious, in particular without in situ trap. These effects were corroborated by the DFT calculations. The reaction mechanisms, such as the structure of the active species in the deprotonation event, the reaction pathways by each postulated LiTMP complex, the stabilization effects by in situ trapping using zinc species, and some kinetic interpretation, are discussed herein.
\end{abstract}

\section{INTRODUCTION}

Deprotonative lithiation using alkyllithiums and hindered lithium dialkylamides is an efficient way to functionalize regioselectively aromatic compounds. ${ }^{1}$ The method has been widely used, but its scope is nevertheless restricted by the low compatibility existing between polar organolithiums and electrophilic functional groups that can decorate the aromatic substrates. In addition, when employed alone, the lithium bases can exhibit an insufficient reactivity toward non-activated substrates.

To tackle these issues, lithium bases have been combined with Lewis donor ligands (e.g. TMEDA; TMEDA $=N, N, N^{\prime}, N^{\prime}$ tetramethylethylenediamine $)^{2}$ or alkali metal alkoxides (e.g. potassium tert-butoxide, ${ }^{3}$ lithium 2-dimethylaminoethoxide $\left.{ }^{4}\right)$. For the same purpose, other metal bases have been activated with salts (Turbo bases) ${ }^{5}$ or in the form of lithium -ate complexes (e.g. zincates, ${ }^{6}$ cuprates 7$) .{ }^{8}$ Owing to less aggregated bases (increased reactivities) or to less polar organometals (higher compatibility with sensitive substrates), the scope of the reaction has been extended to less activated aromatics and to substrates prone to nucleophilic attack, respectively.

In situ trapping of the generated aryllithiums, by either transmetalation or trans-metal-trapping (TMT), ${ }^{9}$ is another way to achieve these goals. ${ }^{10}$ The aryllithiums formed by reaction with non-nucleophilic lithium amides are rapidly intercepted by com- pounds that may contain silicon, boron, zinc, aluminum and gallium. As a consequence, they do not attack sensitive functions and are more efficiently formed. In this context, LiTMP ${ }^{11}$ (TMP = 2,2,6,6-tetramethylpiperidide) can be employed to ensure roomtemperature deprotometalation of a large range of substrates, and studies notably evidenced $\mathrm{Zn}(\mathrm{TMP})_{2}{ }^{12} \mathrm{ZnCl}_{2}{ }^{13} \mathrm{ZnCl}_{2} \cdot 2 \mathrm{LiCl}^{13}$ and $\mathrm{ZnCl}_{2}$. TMEDA ${ }^{14}$ as efficient in situ traps for this purpose. If it is recognized from NMR, ${ }^{11,15}$ theoretical calculations, ${ }^{15}$ and experimental data ${ }^{16}$ that the synergy observed in the reactions using these pairs results from reversible deprotolithiation shifted by in situ trapping by zinc species (lithium amide acting in tandem with separated zinc species), little is known about the precise deprotonation pathway.

Thus, if the LiTMP base plays an important role in organic synthesis due to both strong Brønsted basicity and low nucleophilicity towards electrophiles (e.g. carbon centers), ${ }^{17}$ being used either to accumulate aryllithiums from activated arenes including heterocycles, or in the presence of in situ traps for less activated arenes, there is still much to learn about reaction pathways using LiTMP.

By using diffusion ordered NMR spectroscopy (DOSY), LiTMP.2LiCl ( \pm TMEDA) was pinpointed as the possible active species of the basic combination in situ prepared from $\mathrm{ZnCl}_{2}$.TMEDA and LiTMP in a 1:3 ratio, and supposed to be 1:1 LiTMP-Zn(TMP $)_{2}{ }^{11}$ Recently, LiTMP monomers and dimer 
(triple ion) were proposed as reaction intermediates to rationalize ortho-lithiations of activated arenes. ${ }^{18}$

Herein, we report our experimental and theoretical investigations on the mechanism of LiTMP-mediated deprotometalation of methoxy-substituted arenes, notably concerning the impact of additives such as $\mathrm{LiCl}$ and TMEDA, and of the subsequent in situ trapping step by $\mathrm{Zn}(\mathrm{TMP})_{2}$.

\section{RESULTS AND DISCUSSION}

The solid-state and solution structures of LiTMP depend on Lewis donor solvents or ligands. ${ }^{19}$ While LiTMP can exist as a $\mathrm{C}_{4 \mathrm{~h}}$ cyclotetramer ${ }^{20}$ or a $\mathrm{C}_{3 \mathrm{~h}}$ cyclotrimer ${ }^{21}$ in the crystal, or a mixture of trimers and tetramers in hydrocarbon solution, ${ }^{22}$ deaggregation takes place in the presence of THF (THF = tetrahydrofuran) to give a cyclodimer in which each metal is solvated. ${ }^{23}$ More precisely, ${ }^{7} \mathrm{Li}$ NMR spectroscopy shows monomer-dimer equilibrium, with the former favored at higher concentrations. ${ }^{23-24}$

Probably by reason of more important steric hindrance, the Li-O bond of the THF-solvated cyclodimer solid-state structure is larger in the case of LiTMP than observed for LiDA (DA = diisopropylamide). ${ }^{23}$ Replacing THF by bidentate TMEDA even causes dimer opening to afford the hemisolvated 'open dimer' TMEDA.(LiTMP $)_{2}{ }^{25}$ in addition to monomer species. ${ }^{17}$ On dissolution, the 'open dimer' seems to be cleaved into LiTMP and monomeric TMEDA.LiTMP. ${ }^{26}$

In the case of $\mathrm{LiDA}$, solvating competition experiments between THF and TMEDA were performed, and lithium showed a preference for the former. ${ }^{27}$ Nevertheless, for LiTMP, THF and TMEDA equally coordinate the amide metal. ${ }^{17}$

In the presence of other lithium species (e.g. lithium halides), lithium amides can form mixed aggregates. In particular, ${ }^{6} \mathrm{Li}$ and ${ }^{15} \mathrm{~N}$ NMR studies on $0.1 \mathrm{M}$ THF solutions of LiTMP allowed the mixed dimer LiTMP-LiCl and mixed trimers 2LiTMP-LiCl to be identified in the presence of $\mathrm{LiCl}$ ( 0.3 to 1.2 equiv) at temperatures around $-100{ }^{\circ} \mathrm{C} .{ }^{24 b} \mathrm{~A}$ similar observation was made using $\mathrm{LiBr}$ and, with both salts, the mixed dimers LiTMP-LiX are favored by using stoichiometric amounts of salt. ${ }^{24 b, 28}$ Thus, TMEDA and $\mathrm{LiCl}$, both generated by reacting $\mathrm{ZnCl}_{2}$.TMEDA with LiTMP, might possibly be present in deprotonating species and modify reaction pathways. $^{29}$

Collum and co-workers have studied the impact of $\mathrm{LiCl}$ on LiDA-mediated aromatic deprotometalation in THF under nonequilibrium conditions (low temperatures). ${ }^{30}$ For example, by using 1-chloro-3-(trifluoromethyl)benzene as substrate, the authors observed different transition states depending on if $\mathrm{LiCl}$ is present or not. ${ }^{31}$ Without lithium salt, LiDA deaggregation (conversion of the cyclodimer to the open dimer, and possibly to the monomer $)^{32}$ is the rate-limiting step, and (C2) proton transfer involves dimerbased triple ion transition state. In contrast, $\mathrm{LiCl}$ allows $\mathrm{LiDA}$ to be deaggregated, making (C6) proton transfer rate-limiting, step rather based on solvated LiDA monomer. Two mechanisms, either through triple-ion-like species with possible bridging THF, or through three- and four-rung ladders, were proposed for such LiClmediated LiDA deaggregation. ${ }^{30}$ Nevertheless, these conclusions are both substrate- and temperature-dependent ( $\mathrm{LiCl}$ can catalyze at a temperature and inhibit at another one), ${ }^{33}$ and do not reflect what happens when LiTMP is used.

Mack and Collum recently compared LiDA- and LiTMPmediated deprotometalation of substituted benzenes in THF, and showed reactions with the latter 5-500 times faster than with the former. ${ }^{18}$ By using LiTMP, large isotope effects were noticed in agreement with rate-limiting proton transfers. Less favored stabilizing aggregation is expected using LiTMP due to higher steric hindrance. Toward 1,3-bis(trifluoromethyl)benzene, LiDA reversibly deprotonates the more acidic site between the substituents whereas LiTMP irreversibly attacks the less hindered 4 position. The deprotolithiation mechanisms involving LiTMP are substrate-dependent, with transition states based either on triple ions or on solvated monomers.

Thus, even if $\mathrm{LiCl}$ can impact LiDA-mediated deprotonation transition states, this salt is absent from their composition. As a consequence, it seems most unlikely that LiTMP. $2 \mathrm{LiCl}$ could be the active species in deprotonation-trapping sequences. So, we have gone in search of a suitable substrate to investigate the impact of $\mathrm{LiCl}$ and TMEDA in the course of reactions with LiTMP. To this purpose, we selected three aromatic substrates, 3-methoxypyridine (1a), anisole (2a) and 4-bromoanisole (3a).

\section{Experimental Study}

3-Methoxypyridine (1a) can be functionalized at its 2 position upon treatment with n-BuLi.TMEDA, ${ }^{34}$ mesityllithium ${ }^{35}$ or TMPMgCl. $\mathrm{LiCl}^{36}$ in THF. Mixtures of 2- and 4-substituted derivatives are formed either by using LiDA in the presence of chlorotrimethylsilane as in situ trap, ${ }^{35}$ or with the base in situ prepared from $\mathrm{ZnCl}_{2}$.TMEDA and LiTMP in a $1: 3$ ratio (1:1 LiTMP$\left.\mathrm{Zn}(\mathrm{TMP})_{2}\right) .{ }^{12,37}$ Regioselective deprotometalation at the 4 position takes place either by using hindered TMP-zincate $\mathrm{Li}(\mathrm{TMP}) \mathrm{Zn}\left({ }^{\mathrm{t}} \mathrm{Bu}\right)_{2}$ in $\mathrm{THF}^{38}$ or $(\mathrm{PMDETA})_{2} \mathrm{~K}_{2} \mathrm{Mg}\left(\mathrm{CH}_{2} \mathrm{SiMe}_{3}\right)_{4}$ (PMDETA $=N, N, N^{\prime}, N$ " $N$ "-pentamethyldiethylenetriamine) in hexane. $^{39}$

Scheme 1. Deprotometalation of 3-methoxypyridine (1a) using LiTMP followed by iodolysis

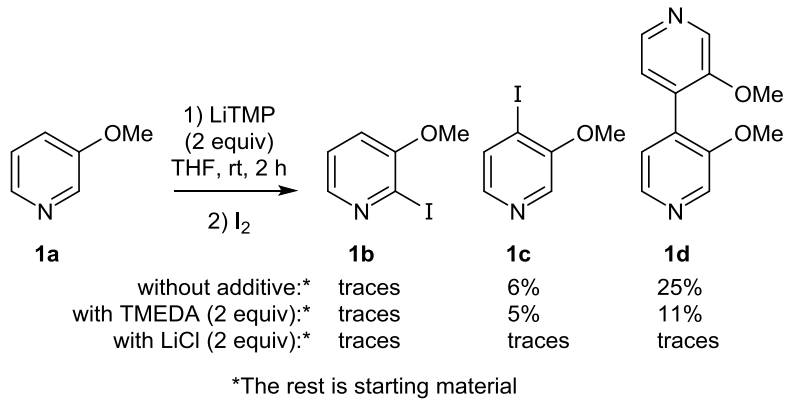

When 3-methoxypyridine (1a) was reacted with LiTMP (2 equiv) in THF for $2 \mathrm{~h}$ at room temperature (rt) before iodolysis, the results showed that the corresponding lithio product(s) could not be accumulated due to formation of the symmetrical dimer 1d. ${ }^{40}$ Things were not improved in the presence of TMEDA or $\mathrm{LiCl}$ (Scheme 1). Note that from isomeric 2-methoxypyridine, only traces of unidentified products were obtained under similar conditions whereas starting material was recovered in the presence of 
$\mathrm{LiCl}$ ( 2 equiv). Therefore, methoxypyridines do not appear as suitable substrates for our study.

LiTMP-mediated deprotometallation of anisole is far from being quantitative. $^{41}$ It is nevertheless possible to evaluate the effect of TMEDA and $\mathrm{LiCl}$ on the course of the reaction (Table 1 ). The next experiments were thus performed from anisole (2a) in THF under thermodynamic conditions using 3 equivalents of LiTMP. Without additive, it resulted in a low $20 \%$ conversion, as evidenced by subsequent trapping with iodine to afford $\mathbf{2 b}$ (entry 1 ). The presence of TMEDA ( 3 equiv) proved to have no effect on the course of the reaction (entry 2), as well as traces of $\mathrm{LiCl}$ (entry 3 ). In contrast, when 3 equivalents of $\mathrm{LiCl}$ were present (in the presence or absence of TMEDA), the conversion dropped to $4-5 \%$ (entries 4 and 5).

Table 1. Deprotometalation of anisole (2a) using LiTMP followed by iodolysis

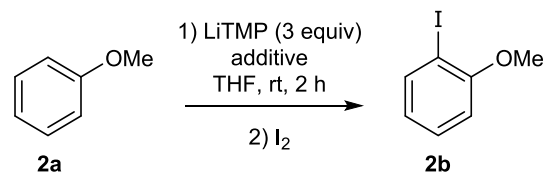

\begin{tabular}{lll}
\hline Entry & Additive & 2b:2a ratio \\
\hline 1 & - & $20: 80$ \\
2 & TMEDA (3 equiv) & $20: 80$ \\
3 & $\operatorname{LiCl}$ (0.02 equiv) & $20: 80$ \\
4 & $\operatorname{LiCl}$ (3 equiv) & $5: 95$ \\
5 & TMEDA (3 equiv) $+\operatorname{LiCl}(3$ equiv) & $4: 96$ \\
\hline
\end{tabular}

${ }^{a}$ Ratio determined from the ${ }^{1} \mathrm{H}$ NMR spectrum of the crude.

In order to confirm these findings, we decided to select a more reactive substrate, and chose 4-bromoanisole ${ }^{42}$ (3a) for this purpose (Table 2). By carrying out the reaction using 2 equivalents of LiTMP at $-40{ }^{\circ} \mathrm{C}$ for $15 \mathrm{~min}$ before iodolysis, 4-bromo-2iodoanisole $(3 \mathbf{b})$ was obtained in a $\sim 1: 1$ ratio together with the substrate $3 \mathbf{a}$ (entry 1 ). In the presence of $\mathrm{LiCl}$ ( 2 equiv), a 1:4 ratio was noticed instead (entry 2). A similar drop was observed when the reaction was conducted at $-50{ }^{\circ} \mathrm{C}$ (entries 3 and 4 ). These results confirm that $\mathrm{LiCl}$ has a negative impact on the course of the reactions of methoxy-substituted arenes with the LiTMP base.

In situ zinc species are capable of exerting a strong effect on the efficiency of the LiTMP-mediated deprotolithiation of methoxysubstituted arenes by intercepting the aryllithium generated (e.g. by the equilibrium reaction between anisole and LiTMP). ${ }^{9 d, 10}$ Thus, starting from anisole (2a), we studied the effect of additives on the reaction with LiTMP (Table 3).
Table 2. Deprotometalation of 4-bromoanisole (3a) using LiTMP followed by iodolysis

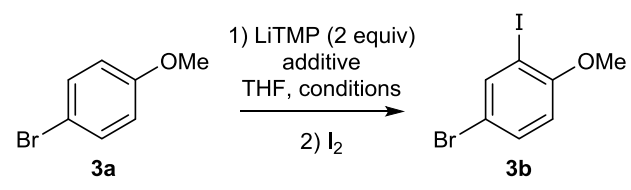

\begin{tabular}{llll}
\hline Entry & Additive & Conditions & $3 \mathbf{b}: 3$ ratio $^{a}$ \\
\hline 1 & - & $-40{ }^{\circ} \mathrm{C}, 15 \mathrm{~min}$ & $47: 53$ \\
2 & $\mathrm{LiCl}(2$ equiv) & $-40{ }^{\circ} \mathrm{C}, 15 \mathrm{~min}$ & $18: 82$ \\
3 & - & $-50{ }^{\circ} \mathrm{C}, 15 \mathrm{~min}$ & $35: 65$ \\
4 & $\mathrm{LiCl}(2$ equiv) & $-50^{\circ} \mathrm{C}, 15 \mathrm{~min}$ & $8: 92$ \\
\hline
\end{tabular}

${ }^{a}$ Ratio determined from the ${ }^{1} \mathrm{H}$ NMR spectrum of the crude.

We first tried to use $\mathrm{ZnCl}_{2}$.TMEDA to in situ intercept (before iodolysis) the generated aryllithium, but we rapidly realized that it is not a suitable zinc species in the case of this weakly activated arene. Indeed, when 1 equivalent of LiTMP was employed between $-20{ }^{\circ} \mathrm{C}$ to $\mathrm{rt}$, only starting anisole (2a) was recovered, probably because added LiTMP directly reacts with $\mathrm{ZnCl}_{2}$. TMEDA (entry 1). A low $20 \%$ conversion was recorded by using 2 equivalents of LiTMP (entry 2) whereas complete reaction was only reached with 3 equivalents (entry 3 ). Similar results were noticed with $\mathrm{ZnCl}_{2}$ (entry 4), and the presence of $\mathrm{LiCl}$ ( 1 equiv) did not affect this conversion (entries 5 and 6).

We next check the ability of putative $\mathrm{Zn}(\mathrm{TMP})_{2}{ }^{43}$ in situ generated from $\mathrm{ZnCl}_{2}$.TMEDA and LiTMP in a 1:2 ratio, to work as an in situ trap. When 1 equivalent of LiTMP was employed at $\mathrm{rt}$ for 2 $\mathrm{h}$, the iodide $\mathbf{2} \mathbf{b}$ was quantitatively formed (entry 7 ). In contrast, by keeping the reaction mixture at $-20^{\circ} \mathrm{C}$, the conversion dropped to $14 \%$ (entry 8 ). We thus chose $0{ }^{\circ} \mathrm{C}$ as intermediate contact temperature to evaluate the effect of the additives. Under these conditions, the iodide $\mathbf{2 b}$ was formed with a $55 \%$ conversion (entry 9 ), and TMEDA (1 equiv) has no effect on the reaction (entry 10). When LiTMP was stirred with $\mathrm{LiCl}$ before its addition to the reaction mixture containing anisole (2a) and preformed $\mathrm{Zn}(\mathrm{TMP})_{2}$, the conversion was slightly reduced to $47 \%$ ( 1 equiv of additive, entry 11 ) and $40 \%$ ( 2 equiv of additive, entry 12 ).

Thus, whereas TMEDA seems to have no effect on the course of the reactions, the presence of $\mathrm{LiCl}$ is deleterious, in particular without in situ trap. 
Table 3. Deprotometalation of anisole (2a) using LiTMP followed by iodolysis

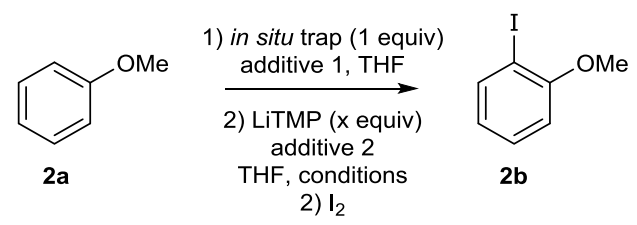

\begin{tabular}{|c|c|c|c|c|c|c|}
\hline Entry & In situ trap & Additive 1 & $\mathrm{x}$ & Additive 2 & Conditions & $2 \mathbf{b}: 2 \mathrm{a}$ ratio ${ }^{a}$ \\
\hline 1 & $\mathrm{ZnCl}_{2} \cdot \mathrm{TMEDA}$ & - & 1 & & $-20^{\circ} \mathrm{C}$ then $\mathrm{rt}, 2 \mathrm{~h}$ & $0: 100$ \\
\hline 2 & $\mathrm{ZnCl}_{2} \cdot \mathrm{TMEDA}$ & - & 2 & & $-20^{\circ} \mathrm{C}$ then $\mathrm{rt}, 2 \mathrm{~h}$ & $20: 80$ \\
\hline 3 & $\mathrm{ZnCl}_{2} \cdot \mathrm{TMEDA}$ & - & 3 & & $-20^{\circ} \mathrm{C}$ then $\mathrm{rt}, 2 \mathrm{~h}$ & $100: 0$ \\
\hline 4 & $\mathrm{ZnCl}_{2}$ & - & 3 & & $-20^{\circ} \mathrm{C}$ then $\mathrm{rt}, 2 \mathrm{~h}$ & $100: 0$ \\
\hline 5 & $\mathrm{ZnCl}_{2} \cdot \mathrm{TMEDA}$ & $\mathrm{LiCl}$ (1 equiv) & 3 & & $-20^{\circ} \mathrm{C}$ then $\mathrm{rt}, 2 \mathrm{~h}$ & 100:0 \\
\hline 6 & $\mathrm{ZnCl}_{2}$ & $\mathrm{LiCl}$ (1 equiv) & 3 & & $-20^{\circ} \mathrm{C}$ then $\mathrm{rt}, 2 \mathrm{~h}$ & 100:0 \\
\hline 7 & $\mathrm{Zn}(\mathrm{TMP})_{2}{ }^{b}$ & - & 1 & & $-20^{\circ} \mathrm{C}$ then $\mathrm{rt}, 2 \mathrm{~h}$ & 100:0 \\
\hline 8 & $\mathrm{Zn}(\mathrm{TMP})_{2}{ }^{b}$ & - & 1 & & $-20^{\circ} \mathrm{C}, 2 \mathrm{~h}$ & $14: 86$ \\
\hline 9 & $\mathrm{Zn}(\mathrm{TMP})_{2}{ }^{b}$ & - & 1 & & $-20^{\circ} \mathrm{C}$ then $0^{\circ} \mathrm{C}, 2 \mathrm{~h}$ & $55: 45$ \\
\hline 10 & $\mathrm{Zn}(\mathrm{TMP})_{2}{ }^{b}$ & - & 1 & TMEDA ( 1 equiv $)^{c}$ & $-20^{\circ} \mathrm{C}$ then $0^{\circ} \mathrm{C}, 2 \mathrm{~h}$ & $54: 46$ \\
\hline 11 & $\mathrm{Zn}(\mathrm{TMP})_{2}{ }^{b}$ & - & 1 & $\mathrm{LiCl}(1 \text { equiv })^{d}$ & $-20^{\circ} \mathrm{C}$ then $0{ }^{\circ} \mathrm{C}, 2 \mathrm{~h}$ & $47: 53$ \\
\hline 12 & $\mathrm{Zn}(\mathrm{TMP})_{2}{ }^{b}$ & - & 1 & $\mathrm{LiCl}(2 \text { equiv })^{d}$ & $-20^{\circ} \mathrm{C}$ then $0^{\circ} \mathrm{C}, 2 \mathrm{~h}$ & $40: 60$ \\
\hline
\end{tabular}

${ }^{a}$ Ratio determined from the ${ }^{1} \mathrm{H}$ NMR spectrum of the crude. ${ }^{b}$ In situ prepared from $\mathrm{ZnCl}$. TMEDA and LiTMP (2 equiv). Note that all the experiments using $\mathrm{Zn}(\mathrm{TMP})_{2}$ in situ prepared from $\mathrm{ZnCl}_{2}$.TMEDA and LiTMP (2 equiv) contain stoichiometric amounts of $\mathrm{LiCl}$, that's why we did not study the effect on the reaction of $\mathrm{LiCl}$ as additive 1 (with $\mathrm{Zn}(\mathrm{TMP})_{2}$ ) but as additive 2 (mixed with LiTMP) in order to favor the presence of mixed dimers or trimers with LiTMP. ${ }^{\circ} \mathrm{LiTMP}$ was stirred for $10 \mathrm{~min}$ at $-20^{\circ} \mathrm{C}$ in the presence of TMEDA before transfer. ${ }^{d} \mathrm{LiTMP}$ was stirred for $20 \mathrm{~min}$ at $-20^{\circ} \mathrm{C}$ in the presence of $\mathrm{LiCl}$ before transfer.

\section{DFT Calculations}

The preliminary studies above showed that anisole is a suitable model substrate to study theoretically its LiTMP-mediated deprotometalation and subsequent interception with $\mathrm{Zn}(\mathrm{TMP})_{2}$. Thus, we conducted DFT calculations at the B3LYP/6-31+G** level of theory to find out which species are involved in the deprotonation and investigate the reaction pathways to afford zinc-trapped arenes.

Though LiTMP.2LiCl \pm TMEDA was proposed as possible active species in the reactions using the basic combination in situ prepared from $\mathrm{ZnCl}_{2}$.TMEDA and LiTMP in a 1:3 ratio (suggestion based on the results of DOSY NMR experiments), ${ }^{11}$ to the best of our knowledge, complexes having 1:2 constitution between LiTMP and $\mathrm{LiCl}$ have never been reported. We thus sought the possible structures of LiTMP.2 $\mathrm{LiCl}$ involved in the deprotonation event. Among those obtained, the transition state structure $\mathbf{T S}_{2 \text { LiCl-2S }}$ described in Scheme 2a was most stable, while it still needs high activation barrier $\left(\Delta G^{\ddagger}+29.9 \mathrm{kcal} / \mathrm{mol}\right)$, making this pathway unlikely. Instead, given that LiTMP can form 1:1 aggregates with lithium salts, ${ }^{24 b, 28}$ we considered the possibility with mixed dimer LiTMP-LiCl as deprotonating species. A slightly lower activation energy $\left(\Delta G^{+}+24.6 \mathrm{kcal} / \mathrm{mol}\right)$ was observed for the pathway via $\mathbf{T S}_{\text {LiCl-2S }}$ (Scheme $2 \mathrm{~b}$ ). Given the uncertain description as " \pm TMEDA,"11 the effects of coordination of TMEDA, instead of the solvent molecules, were examined. The deprotonation of anisole with LiTMP.LiCl.TMEDA complex requires a moderate activation barrier $\left(\Delta G^{\ddagger}+21.0 \mathrm{kcal} / \mathrm{mol}\right.$, Scheme 2c), while we could not identify the reaction pathway using LiTMP.2LiCl.TMEDA as a lithiating reagent.

These results indicated that the composite containing $\mathrm{LiCl}$ should be unlikely to be an active species in the deprotonation of anisole. In addition, 1) LiTMP.2LiCl species have never been observed both in solution and solid phase, 2) even if they could be characterized in solution, we should be careful since it should not necessarily be the active species involved in the reaction, and 3 ) given the numerous mechanistic interpretations for the lithium amide-promoted arene deprotonation by Collum ${ }^{18,30}$ and others, ${ }^{19,44}$ none of lithium amidelithium halide complexes have been proven to be an active deprotonating species. Therefore, the tight combination of experimental and theoretical results led us to conclude that LiTMP-LiCl complexes would not promote the deprotonation of anisole at the orthoposition of a methoxy group. 
Scheme 2. Reaction pathways of the deprotonation of anisole (2a) with LiTMP-LiCl complexes. Energy changes and bond lengths at the B3LYP/6-31+G* level of theory are shown in $\mathrm{kcal} \mathrm{mol}^{-1}$ and $\AA$, respectively. $\mathrm{Me}_{2} \mathrm{O}$ was used as a model of a solvent molecule (THF).

a) LiTMP·2LiCl complex-promoted deprotonation pathway

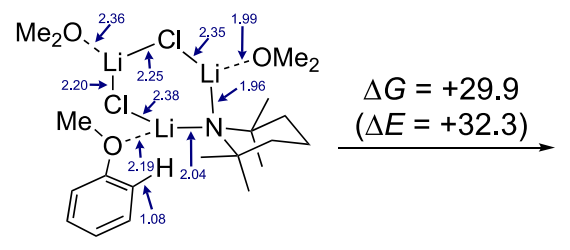

INT1 ${ }_{2 L I C I-2 S}$

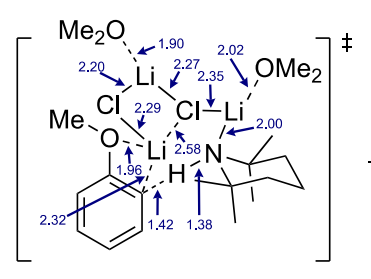

$\mathrm{TS}_{2 \text { LiCl-2S }}$

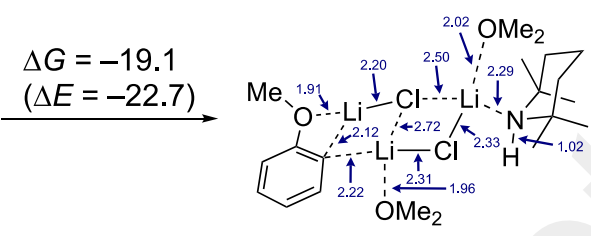

INT2 2 LiCI-2S

b) LiTMP·LiCl complex-promoted deprotonation pathway

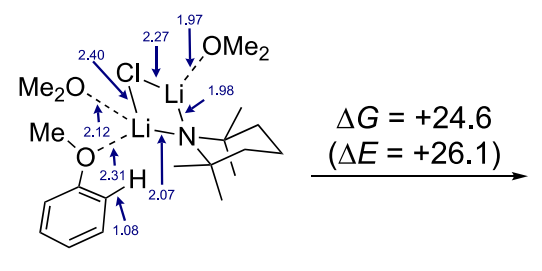

INT1 $1_{\text {LiCl-2S }}$

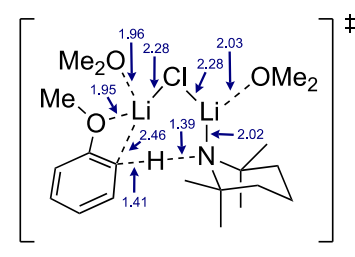

$\mathrm{TS}_{\text {LiCl-2S }}$
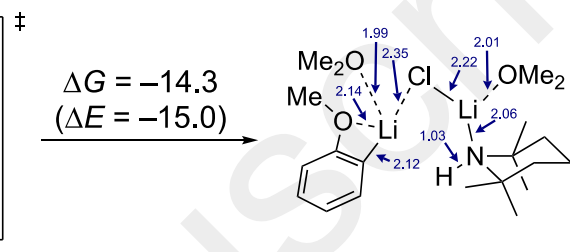

INT2 ${ }_{\text {LiCl-2S }}$

c) LiTMP-LiCl-TMEDA complex-promoted deprotonation pathway

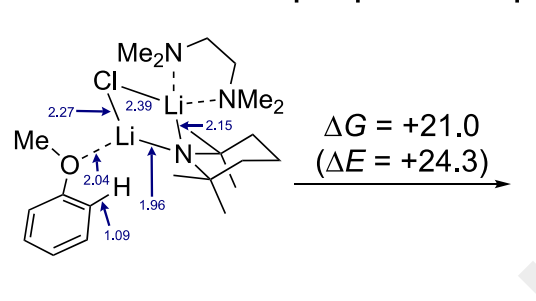

INT1 ${ }_{\text {LiCl-TMEDA }}$

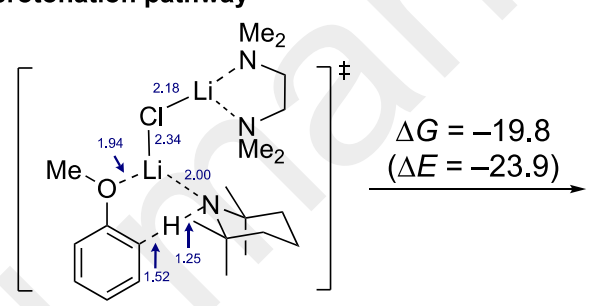

TS $_{\text {LiCl-TMEDA }}$

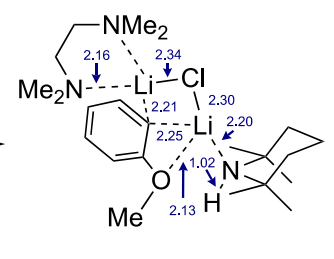

INT2
Since LiTMP is a 10:1 mixture of dimeric and monomeric species in $\mathrm{THF}^{[21-22]}$ we next examined the dimeric LiTMP species in the present deprotonation event. The $\mathrm{C}_{2 \mathrm{~h}}$ LiTMP cyclodimer could take part in the deprotonation. However, the calculated activation energy for $\mathbf{T S}_{\text {dimer }-\mathcal{S}}$ was still high $(+24.0 \mathrm{kcal} / \mathrm{mol})$ and, after the lithiation, insufficient stabilization was observed (INT2 $2_{\text {dimer-S }}$, Scheme 3a).

In addition, the presence of TMEDA facilitated the so-called "open-dimer" formation, ${ }^{25}$ but the required high activation energy $(+37.7 \mathrm{kcal} / \mathrm{mol})$ made this pathway impracticable (Scheme $3 \mathrm{~b}) . \mathrm{A}$ triple ion transition state structure, as reported for the reactive (relatively acidic) arenes, ${ }^{18}$ was also identified (Scheme 3c), and the activation barrier was lower than those of above two $(+20.9$ $\mathrm{kcal} / \mathrm{mol}$ ). The trapping of the resultant deprotonated arene species (INT2 $2_{\text {triple_ion }}$ ) would make this pathway more feasible even with a weakly activated substrate, anisole (2a).

Finally, the reactions of monomeric LiTMP as an active lithiating reagent were investigated. Indeed, the conditions in Table 3 essentially contained $\mathrm{LiCl}$ in the reaction mixture, and the presence of $\mathrm{LiCl}$ can catalyze the deaggregation of dimer to the monomeric LiTMP. Thus, we examined the monomeric LiTMP having varied coordinating molecules (LiTMP.L; L $=0$ to 2 solvent molecules or
TMEDA) as summarized in Figure 1a. The activation barriers were reasonably low enough, and, in particular, two-solvent moleculecoordinating species (i.e. $\mathrm{L}=2 \mathrm{~S}$ ) should promote the deprotonation most preferentially $\left(\Delta G^{\ddagger}=+14.3 \mathrm{kcal} / \mathrm{mol}\right)$. Collum and coworkers reported that the lithiation of 1,3-dimethoxybenzene with LiTMP proceeds with similar species. ${ }^{18}$ Notably, in all cases, the intrinsic reaction coordinate (IRC) calculations revealed the insufficient or small stabilization of lithiated arenes (INT2 $2_{\text {mono-L }}$ ) compared with the initial complexes (INT $1_{\text {mono-L }}$ ), and the small energy gaps between TS $_{\text {mono-L }}$ and INT2 $2_{\text {mono-L. }}$ The former resulted in the insufficient deprotonation using the stoichiometric amount of LiTMP (Table 1, entry 1), ${ }^{18}$ and was compensated by in situ trapping with $\mathrm{Zn}(\mathrm{TMP})_{2}$, which offered the thermodynamic stabilization (Figure $1 \mathrm{~b}$ ). The latter would intrinsically imply the existence of retro-reaction and, thus, the equilibrium of this deprotonation while LiTMP-promoted deprotonations show the kinetic regioselectivity with some arenes. ${ }^{18}$ We speculate that such small equilibrium (not between the two different positions) would not affect the regioselectivity, and the deprotonation at the acidic and more sterically-hindered position might be kinetically hampered under the reaction conditions, which should apparently result in the "kinetically" regioselective lithiation. 
Scheme 3. Reaction pathways of the deprotonation of anisole (2a) with dimeric LiTMP complexes. Energy changes and bond lengths at the $\mathrm{B} 3 \mathrm{LYP} / 6-31+\mathrm{G}^{* *}$ level of theory are shown in $\mathrm{kcal} \mathrm{mol}^{-1}$ and $\AA$, respectively. $\mathrm{Me}_{2} \mathrm{O}$ was used as a model of a solvent molecule (THF).

a) 2LiTMP dimer-promoted deprotonation pathway

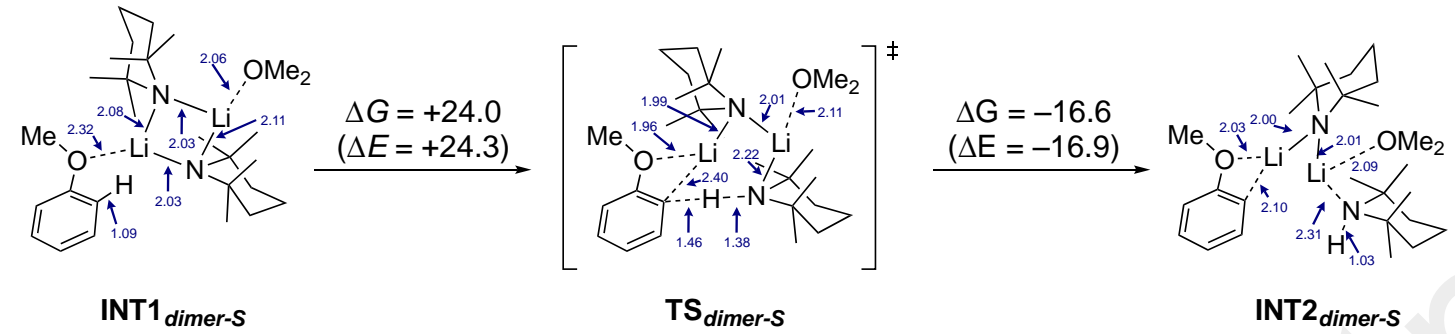

b) 2LITMP·TMEDA “open dimer" complex-promoted deprotonation pathway

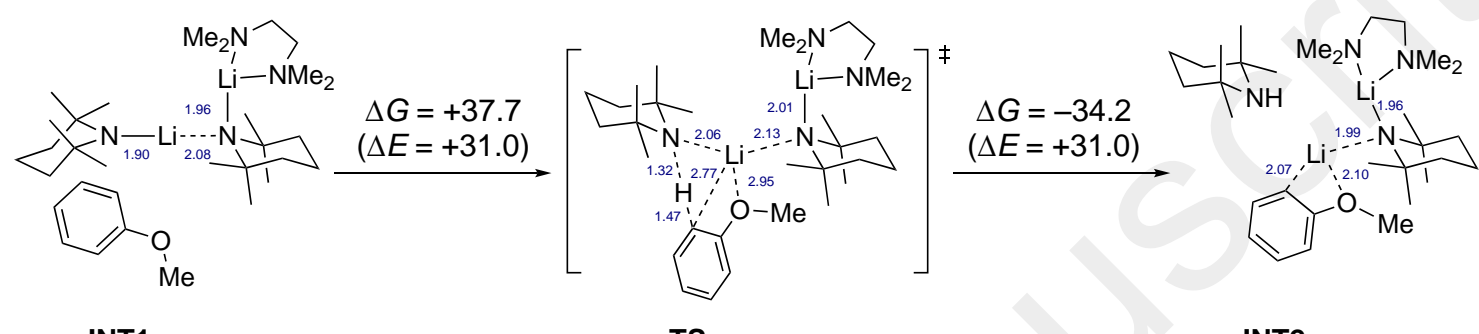

INT1 $1_{\text {open_dimer }}$

TS

INT2 open_dimer

c) Triple ion species-promoted deprotonation pathway

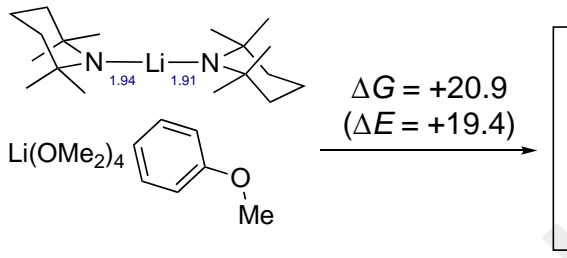

INT1 $1_{\text {triple_ion }}$

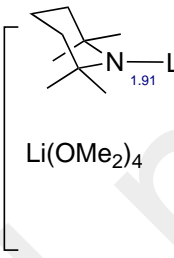

$\mathrm{TS}_{\text {triple_ion }}$

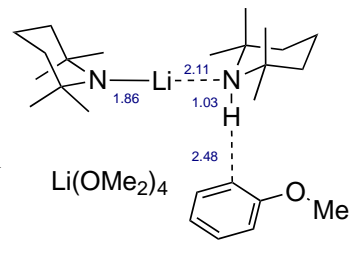

INT2 triple_ion
Thus, the present calculations combined with the experimental results described herein provided not only the information of the active species to facilitate the proton transfer, but also the precise reaction pathway and mechanism of LiTMP-promoted arene deprotonative metalation.

\section{CONCLUSION}

Deprotonative metalation of methoxy-substituted arenes using LiTMP, followed by in situ trapping giving zinc species, was investigated both experimentally and theoretically.

The negative impact of more than the stoichiometric amount of $\mathrm{LiCl}$ on the deprotolithiation step observed experimentally (Tables 1 and 2) was corroborated by the DFT calculations, which suggest that LiTMP-LiCl complexes, including previously postulated LiTMP.2LiCl, ${ }^{11}$ should not be responsible for the orthodeprotonation.
A thorough investigation that consisted in examining (i) the impact of TMEDA and $\mathrm{LiCl}$ on the course of the reactions and (ii) the likelihood of structures for the LiTMP complexes in the reaction pathways by DFT calculations led to the conclusion that the solvated LiTMP monomer should be the actual active species in the deprotonation event; subsequent in situ trapping with $\mathrm{Zn}(\mathrm{TMP})_{2}$ would facilitate the deprotonative metalation process by stabilizing the resultant metalated species.

Further details, such as the precise number of coordinating solvent molecules by kinetic experiments, as well as variation of reaction pathways with different substrates, are currently ongoing. 
Figure 1. a) Reaction pathways of the deprotonation of anisole (2a) with monomeric LiTMP complexes. The inset shows the structure of $\mathrm{TS}_{\text {mono-2s. }}$ b) The formation of $\mathrm{Zn}(\mathrm{TMP})_{2}$-trapped species (INT3zn). Energy changes at the B3LYP/6-31+G** level of theory are shown in $\mathrm{kcal} \mathrm{mol}^{-1}$.

a) LiTMP monomer-promoted deprotonation pathway (L: coordinating molecules)

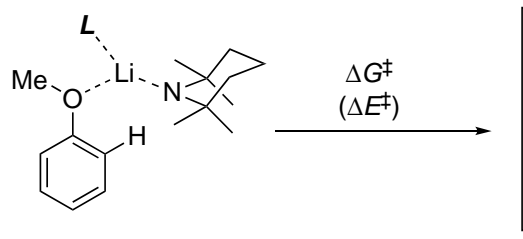

INT1 $1_{\text {mono-L }}$

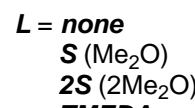

TMEDA

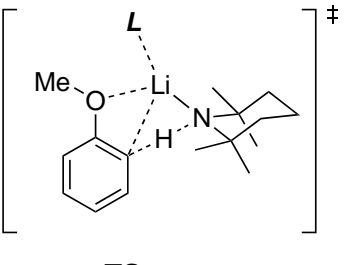

$\mathrm{TS}_{\text {mono-L }}$

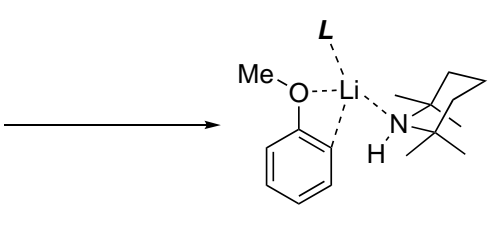

INT2 mono-L

\begin{tabular}{ccc}
\hline$L$ & $\begin{array}{c}\Delta G^{\ddagger} \\
\left(\Delta E^{\ddagger}\right)\end{array}$ & $\begin{array}{c}\Delta \Delta G^{\mathrm{a}} \\
(\Delta \Delta E)^{\mathrm{b}}\end{array}$ \\
\hline none & +18.5 & +4.6 \\
& $(+17.7)$ & $(+2.3)$ \\
$\mathbf{S}\left(\mathrm{Me}_{2} \mathrm{O}\right)$ & +14.9 & +4.7 \\
& $(+15.8)$ & $(+4.3)$ \\
& +14.3 & -1.6 \\
$\mathbf{2 S}\left(2 \mathrm{Me}_{2} \mathrm{O}\right)$ & $(+15.0)$ & $(+0.9)$ \\
TMEDA & +25.1 & +6.9 \\
& $(+19.7)$ & $(+3.1)$ \\
\hline
\end{tabular}

${ }^{\text {a }} \Delta \Delta G=\Delta G(\mathbf{I N T 2}$ mono-L $)-\Delta G\left(\mathbf{I N T} 1_{\text {mono- }}\right)$

${ }^{\mathrm{b}} \Delta \Delta E=\Delta E(\mathbf{I N T 2}$ mono-L $)-\Delta E\left(\mathbf{I N T} 1_{\text {mono- } L}\right)$

b) $\mathrm{Zn}(\mathrm{TMP})_{2}$ trapping of lithiated anisole

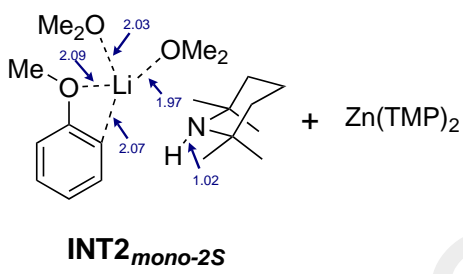

$-\mathrm{TMP}-\mathrm{H}$

$-\mathrm{Me}_{2} \mathrm{O}$

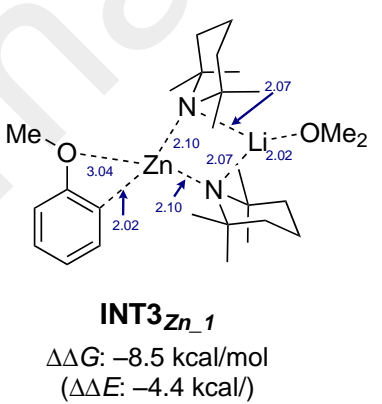

\section{EXPERIMENTAL SECTION}

General information. All the reactions were performed in Schlenk tubes under an argon atmosphere. THF was distilled over sodium/benzophenone. Commercial $\mathrm{LiCl}$ was used after heating under vacuum until complete water removal. Liquid chromatography separations were achieved on silica gel Merck-Geduran Si 60 $(63-200 \mu \mathrm{m})$. Melting points were measured on a Kofler apparatus. ${ }^{1} \mathrm{H}$ and ${ }^{13} \mathrm{C}$ Nuclear Magnetic Resonance (NMR) spectra were recorded on a Bruker Avance III spectrometer at 300 and $75 \mathrm{MHz}$, respectively.

Reaction of 3-methoxypyridine (1a) with LiTMP. To a stirred, cooled $\left(0{ }^{\circ} \mathrm{C}\right)$ solution of 2,2,6,6-tetramethylpiperidine $(0.67 \mathrm{~mL}, 4.0 \mathrm{mmol})$ in THF $(5-6 \mathrm{~mL})$ was added n-BuLi (about $1.6 \mathrm{M}$ hexanes solution, $4.0 \mathrm{mmol}$ ). The mixture was stirred for 15 min at $0{ }^{\circ} \mathrm{C}$ before introduction of 3-methoxypyridine $(0.20 \mathrm{~mL}$, $2.0 \mathrm{mmol})$ at $0-10{ }^{\circ} \mathrm{C}$. After $2 \mathrm{~h}$ at $\mathrm{rt}$, a solution of $\mathrm{I}_{2}(1.0 \mathrm{~g}, 4.0$ $\mathrm{mmol})$ in THF $(7-8 \mathrm{~mL})$ was added. The mixture was stirred overnight before addition of an aqueous saturated solution of $\mathrm{Na}_{2} \mathrm{~S}_{2} \mathrm{O}_{3}$ $(10 \mathrm{~mL})$ and extraction with AcOEt $(3 \times 20 \mathrm{~mL})$. The combined organic layers were dried over $\mathrm{MgSO}_{4}$, filtered and concentrated under reduced pressure. Purification by chromatography on silica gel (eluent: heptane-AcOEt 20:80) led to the following products. 3,3'-Dimethoxy-4,4'-bipyridine (1d) was isolated in $25 \%$ yield (54 mg) as a white powder: $\mathrm{mp} 178-180{ }^{\circ} \mathrm{C}$ (lit. $\left.{ }^{40} 179{ }^{\circ} \mathrm{C}\right)$; its ${ }^{1} \mathrm{H}$ and ${ }^{13} \mathrm{C}$ NMR data are in accordance with those previously described. $^{40}$ 4-Iodo-3-methoxypyridine (1c) was similarly isolated in $6 \%$ yield $(28 \mathrm{mg})$ as a pale yellow powder: $\mathrm{mp} 88-90^{\circ} \mathrm{C}$ (lit. 88 $\left.90{ }^{\circ} \mathrm{C}\right) ;{ }^{12}$ its ${ }^{1} \mathrm{H}$ and ${ }^{13} \mathrm{C}$ NMR data are in accordance with those previously described. ${ }^{12}$ 2-Iodo-3-methoxypyridine (1b) was identified by its ${ }^{1} \mathrm{H}$ NMR spectra. ${ }^{12}$

Reaction of anisole (2a) with LiTMP. To a stirred, cooled (0 ${ }^{\circ} \mathrm{C}$ ) solution of 2,2,6,6-tetramethylpiperidine $(0.67 \mathrm{~mL}, 4.0 \mathrm{mmol})$ 
in THF (5-6 mL) was added n-BuLi (about $1.6 \mathrm{M}$ hexanes solution, $4.0 \mathrm{mmol}$ ). The mixture was stirred for $15 \mathrm{~min}$ at $0{ }^{\circ} \mathrm{C}$ before introduction of anisole $(0.14 \mathrm{~g}, 1.3 \mathrm{mmol})$ at $0-10^{\circ} \mathrm{C}$. After $2 \mathrm{~h}$ at $\mathrm{rt}$, a solution of $\mathrm{I}_{2}(1.0 \mathrm{~g}, 4.0 \mathrm{mmol})$ in THF $(7-8 \mathrm{~mL})$ was added. The mixture was stirred overnight before addition of an aqueous saturated solution of $\mathrm{Na}_{2} \mathrm{~S}_{2} \mathrm{O}_{3}(10 \mathrm{~mL})$ and extraction with $\mathrm{Et}_{2} \mathrm{O}(3$ x $20 \mathrm{~mL}$ ). The combined organic layers were dried over $\mathrm{MgSO}_{4}$, filtered and concentrated (no reduced pressure to avoid evaporation of anisole). The $\mathbf{2 b} \mathbf{b} \mathbf{2 a}$ ratio was determined from the ${ }^{1} \mathrm{H}$ NMR spectra of the crude. The ${ }^{1} \mathrm{H}$ NMR spectrum of 2-iodoanisole (2b) was found as reported previously. ${ }^{45}$

Reaction of 4-bromoanisole (3a) with LiTMP. To a stirred, cooled $\left(0{ }^{\circ} \mathrm{C}\right)$ solution of 2,2,6,6-tetramethylpiperidine $(0.67 \mathrm{~mL}$, $4.0 \mathrm{mmol}$ ) in THF (5-6 mL) was added n-BuLi (about $1.6 \mathrm{M}$ hexanes solution, $4.0 \mathrm{mmol}$ ). The mixture was stirred for $15 \mathrm{~min}$ at $0{ }^{\circ} \mathrm{C}$ before introduction of 4-bromoanisole $(0.25 \mathrm{~mL}, 2.0 \mathrm{mmol})$ at $-50{ }^{\circ} \mathrm{C}$. After $15 \mathrm{~min}$ at $-40^{\circ} \mathrm{C}$, a solution of $\mathrm{I}_{2}(1.0 \mathrm{~g}, 4.0 \mathrm{mmol})$ in THF $(7-8 \mathrm{~mL})$ was added. The mixture was stirred overnight before addition of an aqueous saturated solution of $\mathrm{Na}_{2} \mathrm{~S}_{2} \mathrm{O}_{3}(10$ $\mathrm{mL})$ and extraction with $\mathrm{Et}_{2} \mathrm{O}(3 \times 20 \mathrm{~mL})$. The combined organic layers were dried over $\mathrm{MgSO}_{4}$, filtered and concentrated (no reduced pressure to avoid evaporation of 4-bromoanisole). The $3 \mathbf{b}: 3 \mathbf{a}$ ratio was determined from the ${ }^{1} \mathrm{H}$ NMR spectra of the crude. The ${ }^{1} \mathrm{H}$ NMR spectrum of 4-bromo-2-iodoanisole ( $3 \mathbf{b}$ ) was found as reported previously. ${ }^{46}$

Reaction of anisole (2a) with LiTMP in the presence of a zinc species. To a stirred solution of anisole $(0.14 \mathrm{~g}, 1.3 \mathrm{mmol})$ and $\mathrm{ZnCl}_{2} \cdot \mathrm{TMEDA}^{47}(0.34 \mathrm{~g}, 1.3 \mathrm{mmol})$ in THF $(3-4 \mathrm{~mL})$ cooled at $-20{ }^{\circ} \mathrm{C}$, was added a cooled $\left(-20{ }^{\circ} \mathrm{C}\right)$ solution of LiTMP (prepared by adding $\mathrm{n}-\mathrm{BuLi}$ (about $1.6 \mathrm{M}$ hexanes solution, $4.0 \mathrm{mmol}$ ) to a stirred, cooled $\left(0{ }^{\circ} \mathrm{C}\right)$ solution of 2,2,6,6-tetramethylpiperidine $(0.67 \mathrm{~mL}, 4.0 \mathrm{mmol})$ in THF $(5-6 \mathrm{~mL})$ and by stirring for $15 \mathrm{~min}$ at $\left.0{ }^{\circ} \mathrm{C}\right)$. The mixture was stirred for $2 \mathrm{~h}$ at $\mathrm{rt}$ before dropwise addition of a solution of $\mathrm{I}_{2}(1.0 \mathrm{~g}, 4.0 \mathrm{mmol})$ in THF $(7-8 \mathrm{~mL})$. The mixture was stirred overnight before addition of an aqueous saturated solution of $\mathrm{Na}_{2} \mathrm{~S}_{2} \mathrm{O}_{3}(10 \mathrm{~mL})$ and extraction with $\mathrm{Et}_{2} \mathrm{O}(3 \mathrm{x}$ $20 \mathrm{~mL}$ ). The combined organic layers were dried over $\mathrm{MgSO}_{4}$, filtered and concentrated (no reduced pressure to avoid evaporation of anisole). The $\mathbf{2 b} \mathbf{b} \mathbf{2} \mathbf{a}$ ratio was determined from the ${ }^{1} \mathrm{H}$ NMR spectra of the crude. The ${ }^{1} \mathrm{H}$ NMR spectrum of 2-iodoanisole (2b) was found as reported previously. ${ }^{45}$

\section{ASSOCIATED CONTENT}

Supporting Information. Computational details - Cartesian coordinates and energies. This material is available free of charge via the Internet at http://pubs.acs.org.

\section{AUTHOR INFORMATION}

\section{Corresponding Authors}

*uchi_yama@riken.jp

*florence.mongin@univ-rennes1.fr

\section{ORCID}

Ryo Takita: 0000-0003-4104-9890

Masanobu Uchiyama: 0000-0001-6385-5944

William Erb: 0000-0002-2906-2091
Florence Mongin: 0000-0003-3693-8861

\section{Present Address}

"Département de Chimie, Faculté des Sciences Exactes et Informatique, Université Hassiba Benbouali de Chlef, BP 78C, Ouled Fares, 02000 Chlef, Algeria

\section{Notes}

The authors declare no competing financial interest.

All authors have given approval to the final version of the manuscript.

\section{ACKNOWLEDGMENT}

We thank the Ministère de l'Enseignement supérieur et de la Recherche scientifique Algérien (M.H.), the Centre National de la Recherche Scientifique, the Institut Universitaire de France and Rennes Métropole (F.M.). We acknowledge FEDER founds (D8 VENTURE Bruker AXS diffractometer) and Thermofisher (generous gift of 2,2,6,6-tetramethylpiperidine). The computations were performed using HOKUSAI GreatWave at RIKEN and Research Center for Computational Science at Okazaki, Japan.

\section{REFERENCES}

(1) For general reviews and chapters, see: (a) Gschwend, H. W.; Rodriguez, H. R. Heteroatom-facilitated Lithiations. Org. React. 1979, 26, 1-360; (b) Beak, P.; Snieckus, V. Directed Lithiation of Aromatic Tertiary Amides: An Evolving Synthetic Methodology for Polysubstituted Aromatics. Acc. Chem. Res. 1982, 15, 306-312; (c) Snieckus, V. Directed orthoMetalation. Tertiary Amide and O-carbamate Directors in Synthetic Strategies for Polysubstituted Aromatics. Chem. Rev. 1990, 90, 879-933; (d) Gant, T. G.; Meyers, A. I. The chemistry of 2-oxazolines (1985-present). Tetrahedron 1994, 50, 2297-2360; (e) Schlosser, M. Organometallics in Synthesis 2002, 2nd ed. (Ed.: M. Schlosser), Wiley: New York.

(2) See for example: Betz, J.; Bauer, W. NMR and Calculational Studies on the Regioselective Lithiation of 1-Methoxynaphthalene. J. Am. Chem. Soc. 2002, 124, 8699-8706.

(3) For reviews, see: (a) Schlosser, M. Superbases for Organic Synthesis. Pure Appl. Chem. 1988, 60, 1627-1634; (b) Lochmann, L. Reaction of Organolithium Compounds with Alkali Metal Alkoxides - a Route to Superbases. Eur. J. Inorg. Chem. 2000, 1115-1126.

(4) For a review, see: Gros, P. C.; Fort, Y. Combinations of Alkyllithiums and Lithium Aminoalkoxides for Generation of Functional Pyridine Organometallics and Derivatives. Eur.J. Org. Chem. 2009, 4199-4209.

(5) (a) Wunderlich, S. H.; Knochel, P. (tmp) ${ }_{2} \mathrm{Zn} .2 \mathrm{MgCl}_{2} \cdot 2 \mathrm{LiCl}$ : A Chemoselective Base for the Directed Zincation of Sensitive Arenes and Heteroarenes. Angew. Chem. Int. Ed. 2007, 46, 7685-7688; (b) Klatt, T.; Markiewicz, J. T.; Saemann, C.; Knochel, P. Strategies To Prepare and Use Functionalized Organometallic Reagents. J. Org. Chem. 2014, 79, 4253-4269.

(6) For a review, see: Mulvey, R. E.; Mongin, F.; Uchiyama, M.; Kondo, Y. Deprotonative Metalation using Ate Compounds: Synergy, Synthesis, and Structure Building. Angew. Chem. Int. Ed.2007, 46, 3802-3824.

(7) For a review, see: Harford, P. J.; Peel, A. J.; Chevallier, F.; Takita, R.; Mongin, F.; Uchiyama, M.; Wheatley, A. E. H. New Avenues in the Directed Deprotometallation of Aromatics: Recent Advances in Directed Cupration. Dalton Trans. 2014, 43, 14181-14203.

(8) For general reviews on the use of bimetallic bases and combinations for aromatic deprotometalation, see: (a) Mulvey, R. E. Avant-Garde Metalating Agents: Structural Basis of Alkali-Metal-Mediated Metalation. Acc. Chem. Res. 2009, 42, 743-755; (b) Haag, B.; Mosrin, M.; Ila, H.; Malakhov, V.; Knochel, P. Regio- and Chemoselective Metalation of Arenes and Heteroarenes Using Hindered Metal Amide Bases. Angew. Chem. Int. Ed. 2011, 50, 9794-9824; (c) Mongin, F.; Harrison-Marchand, A. Mixed 
AggregAte (MAA): A Single Concept for All Dipolar Organometallic Aggregates. 2. Syntheses and Reactivities of Homo/HeteroMAAs. Chem. Rev. 2013, 113, 7563-7727.

(9) Trans-metal-trapping was introduced in 2014 for a partial transmetalation using a TMP-aluminate base, i.e. in which lithium remains in the aluminum system: (a) Armstrong, D. R.; Crosbie, E.; Hevia, E.; Mulvey, R. E.; Ramsay, D. L.; Robertson, S. D. TMP (2,2,6,6TetraMethylPiperidide)-Aluminate Bases: Lithium-Mediated Alumination or Lithiation-Alkylaluminium-Trapping Reagents? Chem. Sci. 2014, 5, 3031-3045. It derives from a reinvestigation of mixed lithium-aluminum bases: (b) Naka, H.; Uchiyama, M.; Matsumoto, Y.; Wheatley, A. E. H.; McPartlin, M.; Morey, J. V.; Kondo, Y. An Aluminum Ate Base: Its Design, Structure, Function, and Reaction Mechanism. J. Am. Chem. Soc. 2007, 129, 1921-1930; (c) Naka, H.; Morey, J. V.; Haywood, J.; Eisler, D. J.; McPartlin, M.; Garcia, F.; Kudo, H.; Kondo, Y.; Uchiyama, M.; Wheatley, A. E. H. Mixed Alkylamido Aluminate as a Kinetically Controlled Base. J. Am. Chem. Soc. 2008, 130, 16193-16200. For a review on trans-metaltrapping, see: (d) Uzelac, M.; Mulvey, R. E. Trans-Metal-Trapping: Concealed Crossover Complexes En Route to Transmetallation? Chem. Eur. J. 2018, 24, 7786-7793.

(10) For a review on favored deprotometalations by in situ trapping, see: Mokhtari Brikci-Nigassa, N.; Bentabed-Ababsa, G.; Erb, W.; Mongin, F. In Situ 'Trans-Metal Trapping': An Efficient Way to Extend the Scope of Aromatic Deprotometalation. Synthesis 2018, 50, 3615-3633.

(11) For easier reading, we employed LiTMP, but LiTMP.xLiCl.xTMEDA would be more appropriate. See for example: García-Álvarez, P.; Mulvey, R. E.; Parkinson, J. A. "LiZn(TMP) )", a Zincate or a Turbo-Lithium Amide Reagent? DOSY NMR Spectroscopic Evidence. Angew. Chem. Int. Ed. 2011, 50, 9668-9671.

(12) See for example: Hedidi, M.; Bentabed-Ababsa, G.; Derdour, A.; Halauko, Y. S.; Ivashkevich, O. A.; Matulis, V. E.; Chevallier, F.; Roisnel, T.; Dorcet, V.; Mongin, F. Deprotometalation of Substituted Pyridines and Regioselectivity-computed CH Acidity Relationships. Tetrahedron 2016, 72, 2196-2205, and references cited therein.

(13) See for example: Frischmuth, A.; Fernández, M.; Barl, N. M.; Achrainer, F.; Zipse, H.; Berionni, G.; Mayr, H.; Karaghiosoff, K.; Knochel, P. New In Situ Trapping Metalations of Functionalized Arenes and Heteroarenes with TMPLi in the Presence of $\mathrm{ZnCl}_{2}$ and Other Metal Salts. Angew. Chem. Int. Ed. 2014, 53, 7928-7932.

(14) See for example: Hedidi, M.; Erb, W.; Lassagne, F.; Halauko, Y. S.; Ivashkevich, O. A.; Matulis, V. E.; Roisnel, T.; Bentabed-Ababsa, G.; Mongin, F. Functionalization of Pyridyl Ketones using Deprotolithiation-in situ Zincation. RSC Adv. 2016, 6, 63185-63189.

(15) L'Helgoual'ch, J. M.; Seggio, A.; Chevallier, F.; Yonehara, M.; Jeanneau, E.; Uchiyama, M.; Mongin, F. Deprotonative Metalation of Fivemembered Aromatic Heterocycles using Mixed Lithium-zinc Species. J. Org. Chem. 2008, 73, 177-183.

(16) Amara, R.; Bentabed-Ababsa, G.; Hedidi, M.; Khoury, J.; Awad, H.; Nassar, E.; Roisnel, T.; Dorcet, V.; Chevallier, F.; Fajloun, Z.; Mongin, F. Synthesis of $N$-Aryl and $N$-Heteroaryl $\gamma$-, $\delta$-, and $\varepsilon$-Lactams Using Deprotometalation-Iodination and $N$-Arylation, and Properties Thereof. Synthesis 2017, 49, 4500-4516.

(17) Remenar, J. F.; Lucht, B. L.; Kruglyak, D.; Romesberg, F. E.; Gilchirst, J. H.; Collum, D. B. Lithium 2,2,6,6-tetramethylpiperidide and Lithium 2,2,4,6,6-pentamethylpiperidide: Influence of TMEDA and Related Chelating Ligands on the Solution Structures. Characterization of Higher Cyclic Oligomers, Cyclic Dimers, Open Dimers, and Monomers. J. Org. Chem. 1997, 62, 5748-5754, and references cited therein.

(18) Mack, K. A.; Collum, D. B. Case for Lithium Tetramethylpiperidide-Mediated Ortholithiations: Reactivity and Mechanisms. J. Am. Chem. Soc. 2018, 140, 4877-4883.

(19) (a) Mulvey, R. E.; Robertson, S. D. Synthetically Important AlkaliMetal Utility Amides: Lithium, Sodium, and Potassium Hexamethyldisilaz- ides, Diisopropylamides, and Tetramethylpiperidides. Angew. Chem. Int. Ed. 2013, 52, 11470-11487; (b) Harrison-Marchand, A.; Mongin, F. Mixed AggregAte (MAA): A Single Concept for All Dipolar Organometallic Aggregates. 1. Structural Data. Chem. Rev. 2013, 113, 7470-7562.

(20) Lappert, M. F.; Slade, M. J.; Singh, A.; Atwood, J. L.; Rogers, R. D.; Shakir, R. Structure and Reactivity of Sterically Hindered Lithium Amides and their Diethyl Etherates: Crystal and Molecular Structures of $\left[\mathrm{Li}\left\{\mathrm{N}\left(\mathrm{SiMe}_{3}\right)_{2}\right\}\left(\mathrm{OEt}_{2}\right)\right]_{2}$ and Tetrakis $(2,2,6,6-$ tetramethylpiperidinatolithium). J. Am. Chem. Soc. 1983, 105, 302-304.

(21) Hevia, E.; Kennedy, A. R.; Mulvey, R. E.; Ramsay, D. L.; Robertson, S. D. Concealed Cyclotrimeric Polymorph of Lithium 2,2,6,6Tetramethylpiperidide Unconcealed: X-Ray Crystallographic and NMR Spectroscopic Studies. Chem. Eur. J. 2013, 19, 14069-14075.

(22) Lucht, B. L.; Collum, D. B. Structure of Lithium 2,2,6,6Tetramethylpiperidine (LiTMP) and Lithium 2,2,4,6,6Pentamethylpiperidide (LiPMP) in Hydrocarbon Solution: Assignment of Cyclic Trimer and Tetramer Conformational Isomers. J. Am. Chem. Soc. 1994, 116, 7949-7950.

(23) Armstrong, D. R.; Garcia-Alvarez, P.; Kennedy, A. R.; Mulvey, R. E.; Robertson, S. D. Molecular Structures of THF-Solvated Alkali-Metal 2,2,6,6-Tetramethylpiperidines Finally Revealed: X-ray Crystallographic, DFT, and NMR (including DOSY) Spectroscopic Studies. Chem. Eur. J. 2011, 17, 6725-6730.

(24) (a) Renaud, P.; Fox, M. A. Electrochemical Behavior of Lithium Dialkylamides: The Effect of Aggregation. J. Am. Chem. Soc. 1988, 110, 5702-5705; (b) Hall, P. L.; Gilchrist, J. H.; Harrison, A. T.; Fuller, D. J.; Collum, D. B. Mixed Aggregation of Lithium Enolates and Lithium Halides with Lithium 2,2,6,6-tetramethylpiperidide (LiTMP). J. Am. Chem. Soc. 1991, 113, 9575-9585.

(25) Williard, P. G.; Liu, Q. Y. Aggregated Intermediates in the Aldol Reaction Sequence. Crystal Structure of the Open Dimer of LiTMP.TMEDA. J. Am. Chem. Soc. 1993, 115, 3380-3381.

(26) Armstrong, D. R.; Graham, D. V.; Kennedy, A. R.; Mulvey, R. E.; O'Hara, C. T. A Structural and Computational Study of Synthetically Important Alkali-metal/Tetramethylpiperidide (TMP) Amine Solvates. Chem. Eur. J. 2008, 14, 8025-8034.

(27) Bernstein, M. P.; Romesberg, F. E.; Fuller, D. J.; Harrison, A. T.; Collum, D. B.; Liu, Q. Y.; Williard, P. G. Structure and Reactivity of Lithium Diisopropylamide in the Presence of $N, N, N^{\prime}, N^{\prime}$ tetramethylethylenediamine. J. Am. Chem. Soc. 1992, 114, 5100-5110.

(28) Henderson, K. W.; Dorigo, A. E.; Liu, Q.-Y.; Williard, P. G.; Schleyer, P. v. R.; Bernstein, P. R. Structural Consequences of the Addition of Lithium Halides in Enolization and Aldol Reactions. J. Am. Chem. Soc. 1996, 118, 1339-1347.

(29) For reviews, see: (a) Collum, D. B.; McNeil, A. J.; Ramirez, A. Lithium Diisopropylamide: Solution Kinetics and Implications for Organic Synthesis. Angew. Chem. Int. Ed. 2007, 46, 3002-3017; (b) Hevia, E.; Mulvey, R. E. Split Personality of Lithium Chloride: Recent Salt Effects in Organometallic Recipes. Angew. Chem. Int. Ed. 2011, 50, 6448-6450; (c) Singh, K. J.; Hoepker, A. C.; Collum, D. B. Autocatalysis in Lithium Diisopropylamide-Mediated Ortholithiations. J. Am. Chem. Soc. 2008, 130, 18008-18017; (d) Gupta, L.; Hoepker, A. C.; Singh, K. J.; Collum, D. B. Lithium Diisopropylamide-Mediated Ortholithiations: Lithium Chloride Catalysis. J. Org. Chem. 2009, 74, 2231-2233.

(30) Algera, R. F.; Gupta, L.; Hoepker, A. C.; Liang, J.; Ma, Y.; Singh, K. J.; Collum, D. B. Lithium Diisopropylamide: Nonequilibrium Kinetics and Lessons Learned about Rate Limitation. J. Org. Chem. 2017, 82, 4513-4532.

(31) Hoepker, A. C.; Gupta, L.; Ma, Y.; Faggin, M. F.; Collum, D. B. Regioselective Lithium Diisopropylamide-Mediated Ortholithiation of 1Chloro-3-(trifluoromethyl)benzene: Role of Autocatalysis, Lithium Chloride Catalysis, and Reversibility. J. Am. Chem. Soc. 2011, 133, 7135-7151. 
(32) Hoepker, A. C.; Collum, D. B. Computational Studies of Lithium Diisopropylamide Deaggregation. J. Org. Chem. 2011, 76, 7985-7993.

(33) Liang, J.; Hoepker, A. C.; Algera, R. F.; Ma, Y.; Collum, D. B. Mechanism of Lithium Diisopropylamide-Mediated Ortholithiation of 1,4Bis(trifluoromethyl)benzene under Nonequilibrium Conditions: Condition-Dependent Rate Limitation and Lithium Chloride-Catalyzed Inhibition. J. Am. Chem. Soc. 2015, 137, 6292-6303.

(34) Marsais, F.; Le Nard, G.; Queguiner, G. Regioselective o-Lithiation of 3-Alkoxypyridines; A Convenient Route to New o-Disubstituted Pyridines. Synthesis 1982, 235-237.

(35) Comins, D. L.; LaMunyon, D. H. Ortho Lithiation of 2-, 3-, and 4Methoxypyridines. Tetrahedron Lett. 1988, 29, 773-776.

(36) Tran, L. D.; Daugulis, O. Iron-Catalyzed Heterocycle and Arene Deprotonative Alkylation. Org. Lett. 2010, 12, 4277-4279.

(37) Kadiyala, R. R.; Tilly, D.; Nagaradja, E.; Roisnel, T.; Matulis, V. E.; Ivashkevich, O. A.; Halauko, Y. S.; Chevallier, F.; Gros, P. C.; Mongin, F. Computed $\mathrm{CH}$ Acidity of Biaryl Compounds and Their Deprotonative Metalation by Using a Mixed Lithium/Zinc-TMP Base. Chem. Eur. J. 2013, 19, 7944-7960.

(38) Blair, V. L.; Blakemore, D. C.; Hay, D.; Hevia, E.; Pryde, D. C. Alkali-metal Mediated Zincation of N-heterocyclic Substrates using the Lithium Zincate Complex, (THF) $\mathrm{Li}(\mathrm{TMP}) \mathrm{Zn}(t \mathrm{Bu})_{2}$ and Applications in In Situ Cross Coupling Reactions. Tetrahedron Lett. 2011, 52, 4590-4594.

(39) Baillie, S. E.; Bluemke, T. D.; Clegg, W.; Kennedy, A. R.; Klett, J.; Russo, L.; de Tullio, M.; Hevia, E. Potassium-Alkyl Magnesiates: Synthesis, Structures and Mg-H Exchange Applications of Aromatic and Heterocyclic Substrates. Chem. Commun. 2014, 50, 12859-12862.

(40) Dehmlow, E. V.; Sleegers, A. Syntheses of Hydroxylated Bipyridines. III. Synthesis of Unsymmetrically and Symmetrically Structured Dihydroxybipyridines. Liebigs Ann. Chem. 1992, 953-959.
(41) See for example: Snégaroff, K.; L'Helgoual'ch, J.-M.; BentabedAbabsa, G.; Nguyen, T. T.; Chevallier, F.; Yonehara, M.; Uchiyama, M.; Derdour, A.; Mongin, F. Deprotonative Metalation of Functionalized Aromatics using Mixed Lithium-cadmium, Lithium-indium, and Lithiumzinc Species. Chem. Eur. J. 2009, 15, 10280-10290.

(42) When compared with anisole, 4-bromoanisole benefits from the long-range acidifying effect of bromine: (a) Mongin, F. Long-range Effect of Bromine in the Deprotonative Metalation of Aromatic Compounds. Chimia 2016, 70, 48-52; (b) Slocum, D. W.; Maulden, E. A.; Whitley, P. E.; Reinscheld, T. K.; Jackson, C. S.; Maddox, J. B. Anomalous orthoProton Acidities of the para-Haloanisoles. Eur. J. Org. Chem. 2017, 6882-6884.

(43) Rees, W. S., Jr.; Just, O.; Schumann, H.; Weimann, R. First Structural Characterization of a Zinc-bis(dialkylamide) Compound: Zn $\{$ cyclo$\left.\mathrm{N}\left[\mathrm{C}\left(\mathrm{CH}_{3}\right)_{2}\left(\mathrm{CH}_{2}\right)_{3} \mathrm{C}\left(\mathrm{CH}_{3}\right)_{2}\right]\right\}_{2}$. Polyhedron 1998, 17, 1001-1004.

(44) Reich, H. J. Role of Organolithium Aggregates and Mixed Aggregates in Organolithium Mechanisms. Chem. Rev. 2013, 113, 7130-7178.

(45) L'Helgoual'ch, J.-M.; Bentabed-Ababsa, G.; Chevallier, F.; Yonehara, M.; Uchiyama, M.; Derdour, A.; Mongin, F. Deprotonative Cadmation of Functionalized Aromatics. Chem. Commun. 2008, 5375-5377.

(46) Muraki, T.; Togo, H.; Yokoyama, M. Reactivity and Synthetic Utility of 1-(arenesulfonyloxy)benziodoxolones. J. Org. Chem. 1999, 64, 2883-2889.

(47) Isobe, M.; Kondo, S.; Nagasawa, N.; Goto, T. Trialkylzinclithium [R $\mathrm{R}_{3} \mathrm{ZnLi}$. A New Reagent for Conjugate Addition to $\alpha, \beta$-unsaturated Ketones. Chem. Lett. 1977, 679-682. 
Graphic entry for the Table of Contents (TOC):

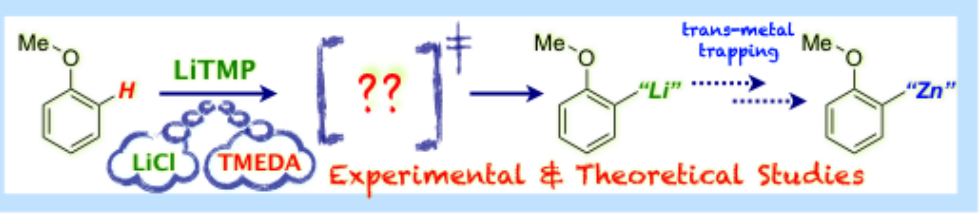

